\title{
Tau in Alzheimer's Disease: Pathological Alterations and an Attractive Therapeutic Target ${ }^{*}$
}

\author{
Jian-lan GU', 2\#, Fei LIU ${ }^{3}$ \\ ${ }^{1}$ Department of Biochemistry and Molecular Biology, School of Medicine, Nantong University, Nantong 226001, China \\ ${ }^{2}$ Key Laboratory of Neuroregeneration and Ministry of Education of Jiangsu, Co-innovation Center of Neuroregeneration, \\ Nantong 226001, China \\ ${ }^{3}$ Department of Neurochemistry, Inge Grundke-Iqbal Research Floor, New York State Institute for Basic Research in \\ Developmental Disabilities, Staten Island, NY 10314, USA
}

(C) The Author(s) 2020

\begin{abstract}
Summary: Alzheimer's disease (AD) is an age-related neurodegenerative disease with two major hallmarks: extracellular amyloid plaques made of amyloid- $\beta(\mathrm{A} \beta)$ and intracellular neurofibrillary tangles (NFTs) of abnormally hyperphosphorylated tau. The number of NFTs correlates positively with the severity of dementia in AD patients. However, there is still no efficient therapy available for $\mathrm{AD}$ treatment and prevention so far. A deeper understanding of $\mathrm{AD}$ pathogenesis has identified novel strategies for the generation of specific therapies over the past few decades. Several studies have suggested that the prion-like seeding and spreading of tau pathology in the brain may be a key driver of AD. Tau protein is considered as a promising candidate target for the development of therapeutic interventions due to its considerable pathological role in a variety of neurodegenerative disorders. Abnormal tau hyperphosphorylation plays a detrimental pathological role, eventually leading to neurodegeneration. In the present review, we describe the recent research progresses in the pathological mechanisms of tau protein in $\mathrm{AD}$ and briefly discuss tau-based therapeutic strategies.
\end{abstract}

Key words: Alzheimer's disease; tau protein; hyperphosphorylation; propagation of tau pathology

Alzheimer's disease (AD) is a dementia associated with age marked by gradual memory loss and cognitive impairment. AD primarily afflicts the elderly and inexorably degenerates the brain tissue of patients. About 50 million people worldwide have been estimated to currently experience dementia and the figure can be more than 152 million in 2050. AD is the sixth major cause of death in the U.S. and the dementia prevalence in people over 65 years in China is $5.14 \%$. Extracellular amyloid plaques and intracellular neurofibrillary tangles (NFTs) are the two distinctive pathological features of AD. NFTs are intraneuronal fibrillary aggregates containing paired helical filaments (PHFs) of hyperphosphorylated $\operatorname{tau}^{[1]}$. The NFTs number is positively associated with the dementia severity in $A D$ patients ${ }^{[2,3]}$. Tau is abnormally hyperphosphorylated at many sites in $\mathrm{AD}$ brain $^{[4,5]}$. Hyperphosphorylated tau loses its normal function, gains neurotoxicity, and

\#Corresponding author, E-mail: ntgjlan@163.com *This project was supported by National Natural Science Foundation of China (No. 31870772). aggregates into $\mathrm{NFTs}^{[6,7]}$. Besides phosphorylation, tau truncation also promotes its aggregation ${ }^{[7]}$. In $\mathrm{AD}$ brain, the tau pathology initiates in the coeruleus/ subcoeruleus complex and in the trans-entorhinal area, progresses gradually toward the limbic system and, occasionally, to the limbic regions and isocortex ${ }^{[8,9]}$. The geographic spread of the tau pathology is seemingly correlated with the AD progression ${ }^{[10,11]}$. The application of tau aggregates from brains with $\mathrm{AD}$ can cause tau pathology in the injection sites and anatomically link brain regions. In vitro experiments have shown that incubation of recombinant tau with heparin can produce tau pathology, similar to the tau pathology propagation in the AD brain ${ }^{[12-14]}$. Prionlike propagation of tau pathology colaborates to the AD evolution ${ }^{[15]}$. Despite joint efforts to investigate the pathophysiological basis of $\mathrm{AD}$, the exact mechanisms remain poorly understood. Worse yet, therapies that looked promising in preclinical research have failed in human clinical trials. Here, we review the progresses in the biology and pathophysiology of AD-related tau and briefly discuss tau-based drug therapies. 


\section{TAU PROTEIN AND TAU PATHOGENESIS}

\subsection{Tau Protein}

Tau is a neuronal protein associated with microtubules that supports the assembly of tubulins in microtubules and steadies them in the brain. The microtubule-associated protein tau (MAPT) gene encoding human tau is localized on chromosome $17 q 21.31$ and it consists of 16 exons. Six tau isoforms varying from 352 to 441 residues, containing two $(2 \mathrm{~N})$, one $(1 \mathrm{~N})$, or zero $(0 \mathrm{~N}) \mathrm{N}$-terminal inserts and four (4R) or three (3R) C-terminal microtubulebinding repeats (MTBRs) are expressed in the adult human brain owing to alternative splicing of exons 2, 3, and 10 ${ }^{[16,17]}$ (fig. 1A). Approximately equimolar quantities of 4R- and 3R-tau are expressed in adult human brain ${ }^{[16,18]}$. Rodent tau has about $90 \%$ identity with human tau, and 4R-tau is expressed primarily in adult rodents and 3R-tau is expressed only in fetal and newborn rodents ${ }^{[18,19]}$. 4R-tau has greater binding affinity to microtubules than 3R-tau and can deslocate the heretefore bound $3 \mathrm{R}-\operatorname{tau}^{[20]}$. Tau is formed by three domains: a projection domain in the N-terminal portion, which protrudes away from the microtubule surface; a Proline-rich domain in the central region, which is responsible for the interaction with proteins containing Src homology 3 (SH3) domains; and an assembly domain in the C-terminal portion, which composes the MTBRs and the flanking regions, and supports microtubule assembly and tau aggregation ${ }^{[21]}$ (fig. 1B). Tau is expressed primarily in axons but it is also observed in the somatodendritic compartment ${ }^{[22,23]}$.

\subsection{Tau Phosphorylation}

Tau is a phosphoprotein whose phosphorylation regulates the tau binding to microtubules. Soluble hyperphosphorylated tau from AD patients holds 5 to 9 phosphate moles per mole of tau, whereas normal tau in healthful human brain contains a mean of 1.9 phosphate moles $^{[4]}$.

Tau can be modified by phosphorylation at multiple threonine (Thr, T), serine (Ser, S) and tyrosine (Tyr, Y) residues. The longest human brain tau isoform, tau441 (Clone \#, tau40), holds 85 possible phosphorylation sites comprising $35 \mathrm{~T}, 45 \mathrm{~S}$ and 5 $\mathrm{Y}$ residues, respectively. Multiple phosphorylation sites are found in PHF-tau in AD brains ${ }^{[24-26]}$ (fig. 2A). Tau phosphorylation at S199, S202/T205, T231, S262, S396 and S422 residues has been indicated to assess the AD progression ${ }^{[27]}$. Tau phosphorylation controls many processes, including binding affinity to microtubules, subcellular distribution and axonal transport ${ }^{[28-30]}$. Aberrant tau hyperphosphorylation induces the dismantle of microtubules and alters their function in the neuronal cytoskeleton organization. Meanwhile, phosphorylated tau accumulates in the neuron cytoplasm, leading to the emergence of tau oligomers and aggregates, such as tangles and fibrillar filaments $^{[31]}$.

Tau hyperphosphorylation in AD brains may result from increased phosphorylation by kinases and/ or decreased dephosphorylation by phosphatases. Tau is abnormally hyperphosphorylated by proline-

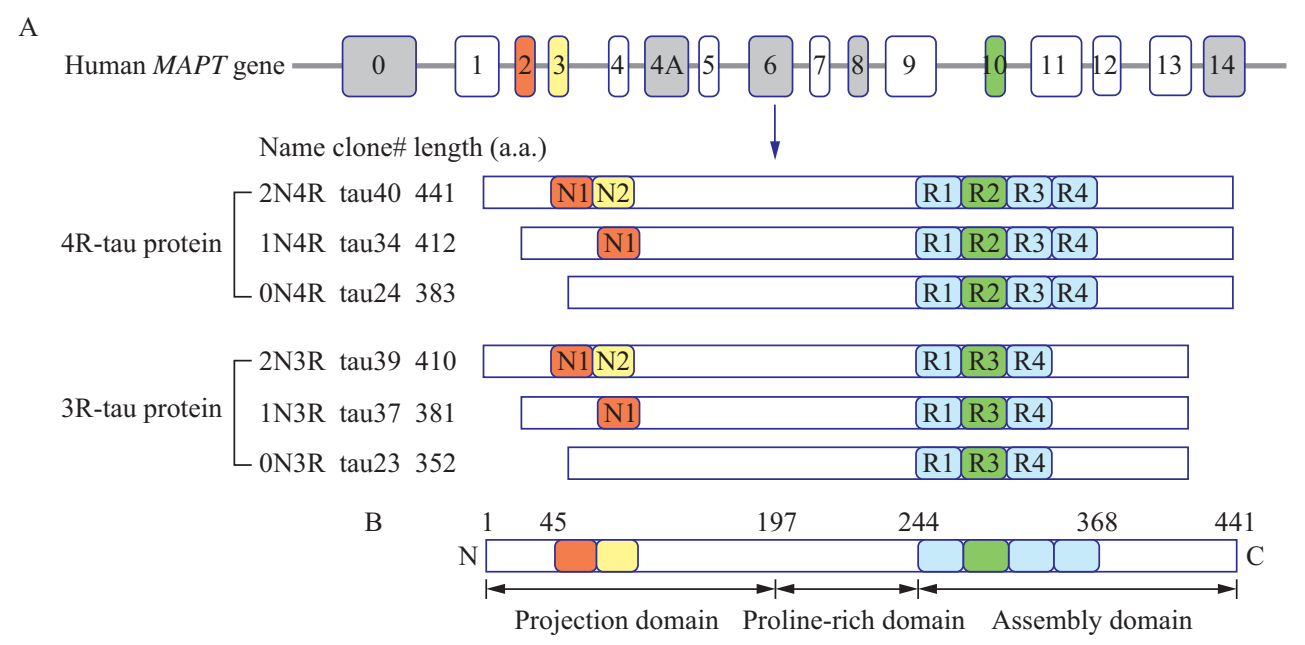

Fig. 1 Human $M A P T$ gene and isoforms of tau proteins

A: Human MAPT gene is localized on chromosome $17 \mathrm{q} 21.31$ and consists of 16 exons. The 5'-UTR of hMAPT mRNA is enconded by exons 0 and 1, whereas part of the 3 '-UTR is enconded by exon 14. Exons 4a, 6, and 8 are present only in big tau in peripheral tissues. Exons 2 and 3 encode two N-terminal insertions of 29 residues each (N1 and N2, in orange and yellow, respectively) and exons 9-12 encode microtubule-binding repeats (MTBRs) (R1, R3, and R4 in blue, R2 in green). Differential splicing of exons 2,3 , and 10 generates isoforms containing zero $(0 \mathrm{~N})$, one $(1 \mathrm{~N})$, or two $(2 \mathrm{~N}) \mathrm{N}$-terminal insertions and three (3R-tau) or four (4R-tau) MTBRs, resulting in six tau isoforms varying from 352 to 441 residues. B: Tau is formed by 3 domains: a projection domain in the N-terminal portion (a.a. 1-197), a Proline-rich domain (a.a. 198-244) and an assembly domain in the C-terminal portion (a.a. 245-441). MAPT, microtubule-associated protein tau; UTR, untranslated region; MTBR, microtubulebinding repeat 
directed kinases (PDPKs) and non-PDPKs ${ }^{[32]}$. S/T residues of tau preceded by a proline (Pro, $\mathrm{P}$ ) residue are phosphorylated by PDPKs, including cyclin dependent kinase 5 (cdk5), C-Jun amino-terminal

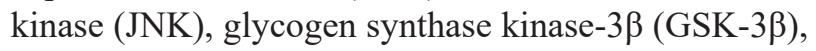
extracellular signal-regulated kinases (ERKs), dual specificity tyrosine-phosphorylation-regulated kinase 1A (Dyrk1A) and cdc2-like kinase 1 (CLK1) ${ }^{[33-36]}$ (fig. 2B). Proline-independent tau $\mathrm{S} / \mathrm{T}$ residues are phosphorylated by non-PDPKs, including cAMP dependent protein kinase A (PKA), casein kinase $1 \delta / \varepsilon$ (CK1 $\delta / \varepsilon)$, calcium/calmodulin-activated protein kinase II (CaMK II ), microtubule affinity-regulated kinases (MARKs), protein kinase R (PKR) and adenosinemonophosphate activated protein kinase (AMPK) ${ }^{[36-40]}$ (fig. 2B). Each of these kinases has different roles regarding tau pathology in $\mathrm{AD}$. In $\mathrm{AD}$ brains, cdk5 phosphorylates tau40 at Ser residues 199, 202, 235, 396 and 404, and Thr residues 181, 205, 212, 217 and 231; GSK-3 $\beta$ phosphorylates all sites phosphorylated by cdk5, except S235 ${ }^{[41]}$; ERK-2 phosphorylates tau at Ser residues 46, 202, 235, 396 and 404, and Thr residues 175, 181, 205, 212, 217, 231 ${ }^{[27]}$ and Dyrk1A phosphorylates tau in vitro at Ser residues 199, 202, 396, 400, 404 and 422, and Thr residues 181, 205, 212, 217 and $231^{[42,43]}$ (fig. 2A). Tau phosphorylation by several of these protein kinases prepares the protein for additional phosphorylation by other kinases ${ }^{[42,44,45]}$. In contrast, there are different protein phosphatases (PPs) types, including protein phosphatases 1 (PP1), 2A (PP2A), 2B (PP2B) and 5 (PP5), as well as tissuenonspecific alkaline phosphatase (TNAP), calcyclin binding protein and Siah-1 interacting protein (CacyBP/ SIP) ${ }^{[46-52]}$ (fig. 2B). PP2A is responsible for about 70\% of all tau dephosphorylation activities in the human brain $^{[47]}$ and its role regarding hyperphosphorylated tau is prejudiced in $\mathrm{AD}^{[53,54]}$. We recently reported that dysregulations of PP2A and GSK-3 $\beta$ affect tau phosphorylation indirectly and directly by affecting activities of each other ${ }^{[55-57]}$. PP2A can also regulate tau phosphorylation by affecting the functions of other tau protein kinases, including cdk5, PKA and CaMK II ${ }^{[17]}$. 1.3 Tau Truncation

Tau is abnormally truncated at several sites ${ }^{[58,59]}$,
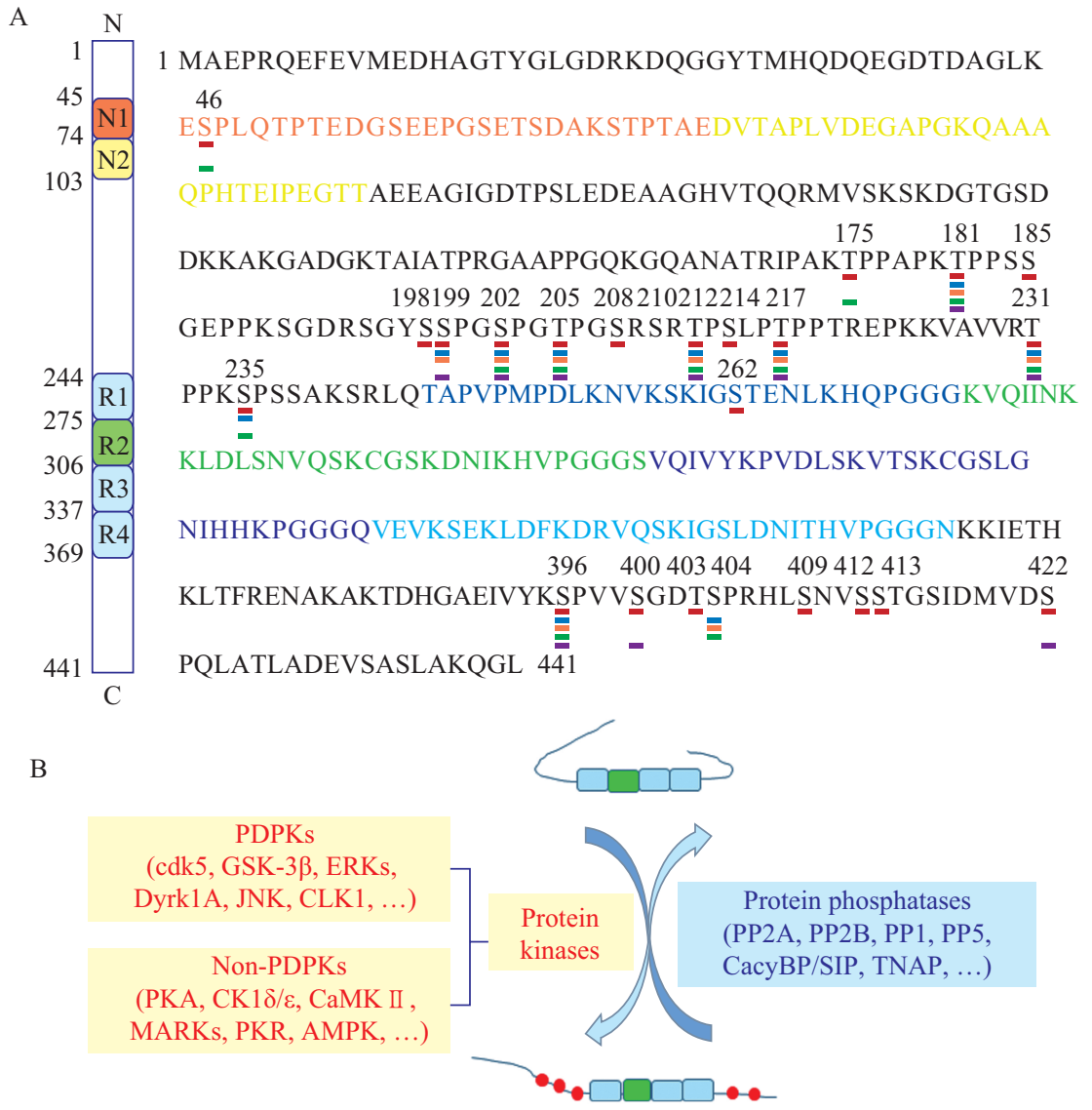

Fig. 2 Phosphorylation of human tau

A: Schematic and sequences of human tau441 showing phosphorylation sites. Tau in PHFs is phosphorylated (red underline) at Ser residues 46, 195, 198, 199, 202, 208, 210, 214, 235, 262, 396, 400, 404, 409, 412, 413 and 422, and Thr residues 175, 181, 205, 212, 217, 231 and 403. Cdk5 phosphorylates tau (blue underline) at Ser residues 199, 202, 235, 396 and 404, and Thr residues 181, 205, 212, 217 and 231. GSK-3 $\beta$ phosphorylates all sites phosphorylated by cdk5, except S235 (orange underline). ERK-2 phosphorylates tau (green underline) at Ser residues 46, 202, 235, 396 and 404, and Thr residues 175, 181, 205, 212, 217 and 231. Dyrk1 A phosphorylates tau (purple underline) at Ser residues 199, 202, 396, 400, 404 and 422, and Thr residues 181, 205, 212, 217 and 231. B: protein kinases and protein phosphatases that mediate tau phosphorylation 
catalyzing by many proteases, including calpains, caspases, asparaginyl endopeptidases (AEPs) and cathepsins $^{[60-62]}$. In NFTs of AD brain, at least three specific tau cleavage sites (N368, E391 and D421) have been recognized and are associated with the Braak stages progression ${ }^{[63-65]}$. Tau in NFTs is $\mathrm{C}$-terminal truncated and the tau predominant forms in the cerebrospinal fluid (CSF) do not have half of the C-terminal portion containing MTBRs. In contrast, tau aggregates from AD brain with high molecular weight (HMW-tau) resistant to SDS and reducing agents do not have the N-terminal region ${ }^{[66,67]}$. Truncated tau is more likely to aggregate than full-length tau ${ }^{[62,68,69]}$. We recently reported that several tau truncations modulate specific sites of phosphorylation, increase tau selfaggregation, and promote the binding to oligomeric tau from $\mathrm{AD}$ brain (AD O-tau) and aggregation seeded by $\mathrm{AD}$ O-tau ${ }^{[70]}$. Among all the truncated forms, Tau151391 causes the most serious pathological disorders and the most potent aggregation effects templated by $\mathrm{AD}$ O-tau in cultured cells in vitro ${ }^{[70]}$. Tau truncation can also promote mitochondrial dysfunction and synaptic deficits $^{[71,72]}$. Tau truncation has an essential function in the tau pathogenesis.

\subsection{Other Post-translational Modifications (PTMs)}

Tau can be also modified at many sites by other PTMs, including acetylation, O-GlcNAcylation, methylation, S-Guanylation, ubiquitination, SUMOylation, nitration, carbamylation and glycation.

\subsubsection{Tau Acetylation More than 20 lysine (Lys,} $\mathrm{K})$ residues located in the the MTBRs and in the tau flanking region are acetylated by CREB-binding protein (CBP) or histone acetyltransferase p300, and tau deacetylation is catalyzed by histone deacetylase (HDAC) 6 or sirtuin 1 (SIRT1) ${ }^{[73-75]}$. Tau acetylation blocks tau degradation, prevents the tau binding to microtubules and elevates tau aggregation ${ }^{[76]}$. Tau acetylation level is increased in the tauopathy brains. Acetyltransferase p300 is up-regulated in AD brains and $\mathrm{AD}$ mice models ${ }^{[76]}$. Intrinsic auto-acetylation of tau is associated to following proteolytic cleavage and the tau fragments production ${ }^{[74,77]}$. SIRT1 levels are decreased in $\mathrm{AD}$ brains ${ }^{[78]}$ and $\mathrm{A} \beta$ treatment reduces SIRT1 expression in cultured neurons ${ }^{[79]}$, perpetuating acetylated tau accumulation. Therefore, enhanced acetylation or reduced deacetylation contributes to the pathological elevation of acetylated tau in $\mathrm{AD}^{[76]}$.

\subsubsection{Tau O-GlcNAcylation O-GlcNAcylation} is a modification of nucleocytoplasmic proteins characterized by monosaccharide $\beta-\mathrm{N}$-acetylglucosamine (GlcNAc) bound to the hydroxy of $\mathrm{S}$ or $\mathrm{T}$ residues. Normally, tau is modified by O-GlcNAcyaltion ${ }^{[80,81]}$. O-GlcNAcylation is performed by the O-GlcNAc transferase (OGT) and O-GlcNAc modification is detached by the O-GlcNAcase $(\mathrm{OGA})^{[82-84]}$. The relative activities of OGT and OGA and the UDP-GlcNAc amount in the cell control the O-GlcNAcylation level ${ }^{[85]}$. Tau site-specific phosphorylation and O-GlcNAcylation compete each other. The reduction in the O-GlcNAcylation level promotes abnormal tau hyperphosphorylation and NFTs formation ${ }^{[86]}$. Calpain I overactivation resulting from $\mathrm{Ca}^{2+}$ overload proteolyzes the neuronal specific glucose transporter 3 (GLUT3), which can impair neuronal uptake of glucose, consequently leading to a decrease in tau O-GlcNAcylation in AD brain ${ }^{[87]}$. Thus, an improvement in brain glucose uptake may be an attractive target for preventing and treating AD.

1.4.3 Tau Ubiquitination Ubiquitination is a very versatile PTM that regulates many aspects of protein functions, such as protein degradation as part of the ubiquitin-proteasome system (UPS) and proteasome independent functions ${ }^{[88,89]}$. Several Lys residues in the tau protein are ubiquitin modified by ubiquitin ligases (E3 ligases), including the $\mathrm{C}$-terminal region of heat shock protein 70-interacting protein (CHIP) and tumor necrosis factor receptor (TNFR)-associated factor 6 (TRAF6) ${ }^{[00,91]}$. Tau ubiquitination was found in neuritic plaques and NFTs in AD brains, in Lewy bodies and filaments related to Parkinson disease (PD) and Pick's disease $(\mathrm{PiD})^{[92,93]}$.

The hippocampus shows decreased proteasome activity in the initial stages of $\mathrm{AD}$ patients ${ }^{[94]}$. The proteasome function is reduced in the presence of aggregated proteins, whose levels can be elevated by tau and $A \beta$ aggregation ${ }^{[95]}$. Soluble PHFs from AD brains are mainly ubiquitylated at residues K254/311/353 of MTBRs $^{[96]}$. Tau monoubiquitylation in PHFs, rather than poly-ubiquitylation, is not sufficient to promote the proteolysis of tau aggregates regulated by UPS ${ }^{[97]}$. Therefore, increasing tau polyubiquitylation and degradation may be a promising therapeutic strategy for $\mathrm{AD}$ treatment ${ }^{[98]}$.

\subsection{Tau Aggregation}

The natively unfolded soluble tau monomers generally display a random coil structure without propensity to aggregate ${ }^{[99]}$. Two motifs formed by six residues $\left({ }_{275}\right.$ VQIINK $_{280}$ and ${ }_{306}$ VQIVYK $\left._{311}\right)$ in tau MTBRs are fundamental for aggregation and formation of tau filaments. These motifs have the propensity to switch their conformation to $\beta$-sheet structures, which are responsible for aggregation of tau monomers to dimers and for pathological aggregation of soluble tau oligomers to insoluble PHFs, and eventually NFTs ${ }^{[100]}$. PHFs in AD have all the six tau isoforms ${ }^{[15]}$.

Aggregation is necessary for neurodegeneration mediated by tau, although the complete mechanism underlying tau aggregation needs to be clarified. Tau aggregation can be promoted by aberrant PTMs and phosphorylation is considered the main trigger for this aggregation. The number of NTFs is positively associated to the dementia severity in $\mathrm{AD}$ patients 
and tau aggregation was originally hypothesized to cause NFTs toxicity ${ }^{[3]}$. Interestingly, researches on transgenic mice and $\mathrm{AD}$ patients indicate that most neurons may die owing to the formation of NFTs. Thanks to the occurrence of dysfunction, synapse loss and cognitive impairment that arise well before NFTs formation, soluble tau oligomers may be the leading neurodegeneration cause, although the precise oligomeric tau species driving neurodegenerative processes have not been identified ${ }^{[37]}$. Phosphorylation or pseudo-phosphorylation of 4R2N (tau40), the largest of the tau isoforms, increases aggregation of tau, while phosphorylation of $4 \mathrm{R} 0 \mathrm{~N}$ (tau24) or $3 \mathrm{R} 2 \mathrm{~N}$ (tau39) decreases it ${ }^{[101,102]}$.

Truncation influences tau aggregation. Tau is truncated at several sites by different proteases ${ }^{[58,103]}$ and the acidic terminal interacts with MTBRs preventing tau aggregation ${ }^{[104]}$. We recently constructed 11 truncations from both the $\mathrm{C}$ - and $\mathrm{N}$-terminal portions of the tau protein according to the reported truncation sites, and then compared the pathological activities of all the truncated forms ${ }^{[70]}$. We observed that deletion of the first 150 or 230 residues of the tau protein increased its self-aggregation, site-specific phosphorylation, and binding to and aggregation seeded by AD O-tau, while the first 50 residues deletion did not have those effects ${ }^{[70]}$. Deletion of the last 50 residues regulated the tau site-specific phosphorylation and promoted tau self-aggregation, which could be seized and seeded to aggregation by AD O-tau, while the last 20 residues deletion did not show significant effects $^{[70]}$. Among all the truncated forms, Tau ${ }_{151-391}$ was the most pathologically active. AD O-tau induced Tau151-391 aggregation in cultured cells and in vitro. The deletion of the first 150 and the last 50 residues protected tau from pathological features and facilitated the tau pathological activities ${ }^{[70]}$. Thus, suppressing tau truncation can be a possible treatment method to inhibit tau pathology in $\mathrm{AD}$ and related tauopathies ${ }^{[70]}$.

Other PTMs can also affect tau aggregation. Similar as phosphorylation, acetylation at some Lys residues, like K18/163/280/281/369 increases the aggregation of $\operatorname{tau}^{[74]}$, while acetylation at many other lysines decreases $\mathrm{it}^{[105]}$. O-GlcNAcylation at $\mathrm{S} 400^{[106]}$, nitration at $\mathrm{Y} 18 / 394^{[107]}$, methylation at multiple residues $^{[108]}$, and S-Guanylation at certain cysteines also decrease tau aggregation ${ }^{[109]}$. SUMOylation at $\mathrm{K} 340^{[110]}$, carbamylation at $\mathrm{K} 280$ and/or K311 ${ }^{[111]}$, and glycation at multiple lysine residues increase tau aggregation $^{[101]}$.

In addition to PTMs, mutations also affect tau aggregation. Tau missense mutations, including G272V, P301L, V337M, and R406W, have a greater tendency to form aggregates, while the MTBR deletion mutation $\Delta \mathrm{K} 280$ reduces the binding affinity to microtubules, strengthens the $\beta$-sheet structures and promotes fibrillization $^{[112,113]}$. Tau exon 10 alternative splicing and the 4R-tau/3R-tau appropriate ratio are important to prevent abnormal fibrillization. 4R-tau, which contains an additional MTBR, binds and promotes microtubule assembly more easily than $3 \mathrm{R}-\operatorname{tau}^{[114]}$. 4R-tau is more likely to trigger polymeration induced by heparin than the association of 4R- and 3R-tau in vitro $^{[115]}$. Besides, several negatively charged cofactors, such as dextran sulfate, heparin, RNA and arachidonic acid, can also promote tau aggregation in vitro ${ }^{[16]}$.

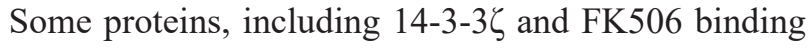
protein 4 (FKBP4), possibly induce tau aggregation by stabilizing the structure prone to aggregation in vitro $^{[117,118] \text {. }}$

\subsection{Prion-like Propagation}

Tau pathology initiates in the coeruleus/ subcoeruleus complex and in the transentorhinal area, then progresses gradually towards the limbic system and, eventually, can reach the isocortex ${ }^{[8,9]}$. The regional distribution of tau lesions is positively related to the cognitive impairment in AD. Tau pathology progresses according to predictable patterns in patients and has been proposed to involve brain networks ${ }^{[9,119,120] . ~ S o m e ~}$ processes, such as templated seeding, cellular uptake, secretion and intercellular transfer by non-synaptic and synaptic paths, are expected to occur for the tau pathology proliferation in the prion-like manner ${ }^{[116,}{ }^{121]}$. It is not clear that tau accumulation can be absorbed by cells through accurate pathways. The accumulation of tau is ingested through macro-pinocytosis ${ }^{[122,123]}$ and heparan sulfate (HS) proteoglycans are required ${ }^{[122]}$. Tau seeds in endosomes in contact with the cytosol, then prompt the accumulation of non-accumulated tau. HS participates in tau hyperphosphorylation in $\mathrm{AD}$ brain, then precedes the tau accumulation ${ }^{[124]}$.

Prion-like mechanisms of tau pathology propagation were first proposed in $2009^{[125]}$. Since then, several studies have suggested that assemblies of tau, when administered extracellularly, may "seed" the generation of aggregates, which then spread to other cells. The propagation of intracellular tau requires seeding, aggregate uptake and release. Even if the tau monomer is absorbed by the cells, from which it can be discharged, it is likely not capable to seed the aggregation. Expressed 4R-tau is not able of being seeded when it does not contain the 275-280 and 306311 regions $^{[123]}$. Tau aggregation inhibitors (TAIs) can then be capable to decrease tau-induced seeding and spreading.

Once a normal protein comes in contact with a misfolded tau protein "seed", it can be transformed into a pathogenic form. The mechanism of this transformation is not yet clear, but it is known that it requires template-mediated conformational changes and that its propagation is carried out by neuronal networks ${ }^{[126,127]}$. Tau proteins are hubs for their own 
aggregation and then serve as "seeds" for further misfolding ${ }^{[40]}$. Dujardin et al examined several aspects of tau obtained from postmortem AD brains in P301S mice and found that the seeding activity correlates with oligomeric/hyperphosphorylated tau levels, rather than the total tau amount ${ }^{[128]}$. The plenty of oligomeric/hyperphosphorylated tau forms is also associated with disease evolution, and high phosphotau (P-tau) levels are correlated with seeding activity. We recently reported that $\mathrm{AD} \mathrm{O}$-tau effectively induced tau aggregation in vivo and in vitro in a prion-like manner ${ }^{[67,70,129,130]}$, which can be the amplification and spread basis of tau pathology throughout AD brain. AD O-tau can arrest normal tau and template it to form nerve fiber bundles in an unsaturated way ${ }^{[31]}$, indicating that the tau pathology can propagate in the human brain via prion-like characteristic of tau "seeds"[131].

In vitro studies have important contributions to the understanding of the basic mechanism of intercellular tau pathological metastasis. For example, in cultured cells, tau "seeds" are able to promote a similar type of tau aggregation in recipient cells and clearly reproduce the morphological characteristics of tau aggregation. Pathological tau involves a variety of molecular pathways in the process of intercellular metastasis ${ }^{[132]}$.

\section{TAU-BASED THERAPEUTIC STRATEGIES}

There are several opportunities for therapeutic intervention at each stage of tau pathology development. However, meaningful significant advances in understanding the AD pathology, a treatment that has been shown to be effective in humans has not yet been found. To date, treatments based on $A \beta$ appear to be ineffective in improving the $\mathrm{AD}$ symptoms. On the other hand, potential therapeutic strategies against tau have appeared to be very promising for the AD treatment (fig. 3). Tau targeted therapies are currently in the early developmental stages, but have great potential for evolution.

\subsection{Tau Expression Inhibition}

Tau protein, as a central molecule in $\mathrm{AD}$ pathology, is toxic to cells directly and mediates $A \beta$ toxicity ${ }^{[133]}$. Thus, inhibition of tau expression may be a promising approach for the AD treatment. Decreased levels of endogenous tau have been indicated to exhibit protective effects against behavioral abnormalities and $\mathrm{A} \beta$-induced cognitive impairments in $\mathrm{AD}$ model mice. Tau knockout (KO) has few side effects in model mice ${ }^{[134]}$, possibly because other proteins associated with microtubules can compensate for tau deficiency to a great extent. If tau monomer levels in cells decrease, the balance governing the formation of aggregates determines that tau assembly will depolymerize, decrease oligomeric tau and aggregate as $\mathrm{PHFs}^{[135]}$. Antisense oligonucleotides (ASOs) or small interfering RNA (siRNA) can reduce tau expression. siRNAs decrease tau pathology and associated functional impairments in both cell and animal models ${ }^{[71]}$. To date, siRNAs have not been examined in clinical tests for $\mathrm{AD}$ or other tauopathies, although they have been employed for other diseases, such as cancer ${ }^{[136,137]}$.

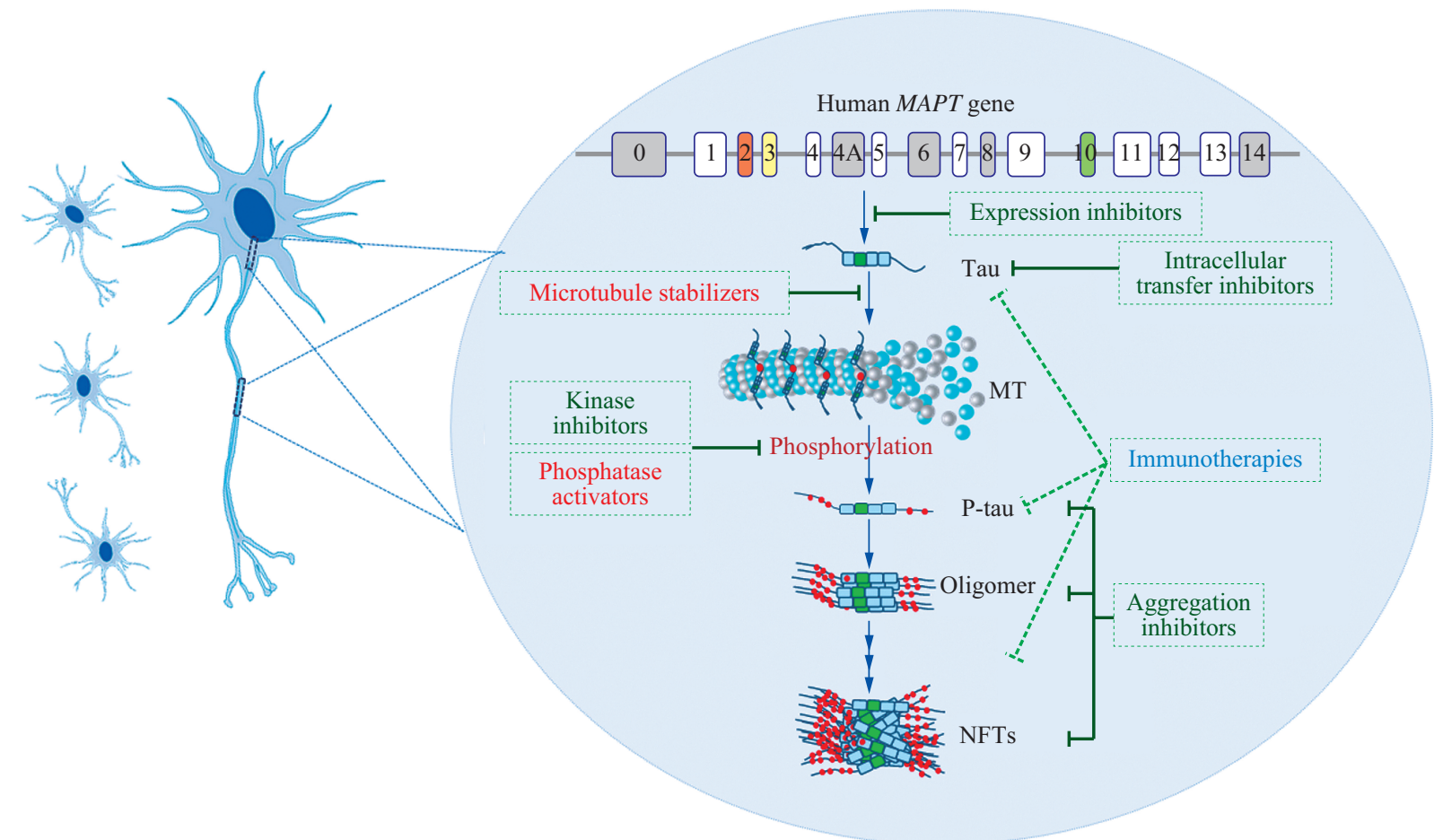

Fig. 3 Therapeutic approaches targeting tau

Tau expression and its pathogenesis and the possible mechanism of disease-modifying agents. MT, microtubule; MAPT, microtubule-associated protein tau; NFTs, neurofibrillary tangles; p-tau, hyperphosphorylated tau 
Several microRNAs, including miR-106b, miR-125b, miR-132/122, and miR-219, regulate tau expression and phosphorylation ${ }^{[138-141]}$. ASOs have been a common experimental method for about 25 years ago, but have lost preference due to side effects. Recently, ASOs have been found to alleviate the progress of spinal muscular atrophy, which can lead to a resurgence of ASOs treatment for various diseases, including tauopathies ${ }^{[142,143]}$. However, additional studies are needed to evaluate whether tau expression inhibition would be advantageous for the $\mathrm{AD}$ treatment.

\subsection{Tau Phosphorylation Inhibition}

Hyperphosphorylated tau proteins are prone to form aggregates and determine tau pathology propagation. Tau hyperphosphorylation inhibition is a therapeutic approach, and tau protein kinases and protein phosphatases exert key roles in evolution of AD. Tau is phosphorylated by kinases, such as cdk5, GSK-3 $\beta$, ERK and Dyrk1A. Lithium chloride ( $\mathrm{LiCl})$, a specific inhibitor against GSK-3 $\beta$ and K252a (a nonspecific inhibitor against cdk5, ERK1 and GSK-3ß), decreases insoluble and hyperphosphorylated tau levels in mice model $\mathrm{s}^{[40]}$. Some small molecule inhibitors that target GSK-3 $\beta$, such as SRN-003-556, CHIR-98014 and SB 216763 are currently at the preclinical stage. Tau protein kinases activities are directly or indirectly associated to tau pathology in several ways, making them an indubitable potential target.

The main phosphatase of tau is PP2A, which can be regarded as the most decisive phosphatase because it is involved in more than $70 \%$ of the total phosphatase events upon tau ${ }^{[47]}$. PP2A mediates tau dephosphorylation and the levels of PP2A and its activators have been found to be down-regulated in $\mathrm{AD}$ brains in comparison with the age-matched controls ${ }^{[33,54]}$. We recently reported the cross-talk between PP2A and GSK-3. PP2A increased GSK$3 \beta$ activity by GSK-3 $\beta$ dephosphorylation at S9 residue. Up-regulated GSK-3 $\beta$, in turn, increased PP2A activity by PP2A methylation through leucine carboxyl methyltransferase 1 (LCMT-1) and/or protein phosphatase methylesterase-1 (PME-1) ${ }^{[55]}$. Therefore, GSK-3 $\beta$ and PP2A mutually regulate and affect tau phosphorylation. Several drugs that target PP2A activity are presently being developed or assessed in clinical tests ${ }^{[24]}$. Tau hyperphosphorylation is a predictive event in the $\mathrm{AD}$ process and can be regarded as a leading strategic therapy against tau protein.

\subsection{Tau Aggregation Inhibition}

Several PTMs decrease the microtubule binding ability of tau and enhance its detachment from the microtubules. This effect conducts to a gradual rise in the intracellular tau levels, which increases the probability of interaction with tau protein, and eventually leads to the tau aggregation. Tau oligomers are the most toxic species that induce neurotoxicity and neurodegeneration in AD. Tau aggregation inhibitors (TAIs) therapy aiming the prevention of the tau pathology prion-like propagation is a considerable strategy that targets tau.

To date, most TAIs are derivatives from methylene blue, including methylthioninium chloride (MTC), Rember TM, and LMT. These TAIs were reported to disrupt tangles and tau filaments, and hinder cognitive deficits in tau transgenic mice ${ }^{[144]}$. MTC is a drug authorized by the FDA for the methemoglobinemia treatment and has been reintroduced to treat $\mathrm{AD}$ and other related tauopathies ${ }^{[40]}$. Although extensive studies have demonstrated that MTC and other methylene derivatives can reverse the PHF proteolytic stability through blocking tau-tau binding without interfering with the tau-tubulin interaction in vitro, their effects are not the same in vitro/in vivo or in clinical trials $\left.{ }^{[145}\right]$. So far, the benefits of these drugs have been limited ${ }^{[145]}$. As an example, LMTX is a second-generation TAI that has not been able to ameliorate functional and cognitive skills in mild to moderate AD patients in phase III clinical trials ${ }^{[24]}$. In contrast, NPT088 is currently used as a TAI in phase I trials ${ }^{[146]}$. It is a fusion protein that recognizes and remodels a number of misfolded proteins, including A $\beta$ and tau. NPT088 can reduce A $\beta$ plaque and phosphorylated tau pathology and enhance cognitive performance in transgenic mice. Another strategy to inhibit tau aggregation is to interfere with the steric zippers formed by two hexapeptide motifs ${ }^{[147]}$. This approach may be fundamental for the design of new drugs against tau.

\subsection{Intercellular Transfer of Tau Inhibition}

Tau aggregates, as well as pathologically misfolded proteins, can migrate from cell to cell and release into the extracellular compartment in a prionlike manner, causing the tau pathology to spread to different regions of brain. This is a therapeutic direction to curb the evolution of tauopathies and other neurodegenerative disorders ${ }^{[148]}$. Numerous studies have shown that targeting tau protein by blocking its intercellular transference can delay the tau pathology in patients with $\mathrm{AD}^{[148]}$. Tau pathology is harmful to neurons, so preventing the pathological propagation of tau aggregates can reasonably reduce the disease impact $^{[40,147]}$. There are three different pathways to block or reduce tau interneuronal transfer, including blocking the tau release, inhibiting tau uptake, and decreasing tau oligomerization and the extracellular tau levels. The tau release block can be targeted on two different sides. After the tau release has been blocked, extracellular levels and availability of tau will decrease, thereby preventing tau uptake by neighboring neuronal cells $^{[149]}$.

\subsection{Microtubule Stabilization}

Impaired normal tau function leads to abnormal axonal transport and microtubule assembly. 
Pathological tau proteins detach from microtubules, leading to microtubules rupture in $\mathrm{AD}$ patients. Therefore, microtubule stabilization is considered to compensate for tau-induced neurotoxicity. Targeting microtubule stabilization is a potential therapeutic strategy in which tau is not the primary focus. The rationale for this therapeutic approach is that microtubule stabilizers have beneficial neuroprotective effects in patients with $\mathrm{AD}^{[150]}$. Taxol-derived epothilone is a small molecule microtubule-stabilizing molecule that can traverse the blood brain barrier (BBB) easily. Thus, it can recover spatial memory defects by reducing hippocampal neuron loss and tau pathology, and reduce the axon number with abnormal morphology and increase the microtubule number in transgenic mice ${ }^{[151-153]}$. Abeotaxane and Davunetide are recently found microtubule stabilizers that have provided advances towards microtubule stabilization, but whose effectiveness in animal models and human trials is unbalanced ${ }^{[135,151]}$. Some other microtubule stabilizers, such as TPI287 and NAP, are in phase I / II clinical trials ${ }^{[135]}$. Thus, there are large gaps to be filled for the development of this strategic approach. This therapeutic strategy targeting microtubule-stabilizing drugs still needs more effective clinical trials results and requires further evaluation.

\subsection{Tau Immunotherapy}

To date, the most promising tau-targeted methodology may be tau immunotherapy. Passive or active immunization through antibodies against P-tau peptides or phosphorylated tau reduces tau pathology and behavioral abnormalities and effectively improve cognitive performance ${ }^{[154]}$. A promising tau-directed monoclonal antibody-based tau immunotherapy using an antibody (BIIB092) against the tau protein $\mathrm{N}$-terminal region lately demonstrated great toleration in a phase $1 \mathrm{~b}$ clinical trial for progressive supranuclear palsy (PSP) ${ }^{[154]}$. But, the phase II trial was interrupted after analysis of futility and a potential reason for the failure was the relatively advanced stage of the disease [https://www.alzforum.org/news/research-news/ abbvies-tau-antibody-flops-progressive-supranuclearpalsy]. Many other tau antibodies, including those obtained from serum, display great selectivity for pathological tau and are promising in preclinical studies ${ }^{[135]}$. Among them, it was highlighted those targeting tau central portions, such as UCB0107, which have been well tolerated and acceptably safe in recent PSP trials. Some antibodies against p-tau (RO6926496, RO7105705), tau fragments (BMS-986168, C2N8E12), tau conformations (anti-tau oligomer-specific antibody), or total tau (ABBV-8E12) are presently being assessed in clinical trials ${ }^{[24,25]}$. Clearly, it is impossible to remove the existing neurodegeneration in $\mathrm{AD}$, but inhibiting the tau propagation to nonaffected brain regions can delay or stop progression of tau pathology. Our recently studies have shown that tau passive immunization with antibody 43D (targeting tau 6-18) blocked the seeding and spreading of Alzheimer hyperphosphorylated tau-induced pathology. This led to a decrease in $A \beta$ pathology and enhanced cognition in $3 \times \mathrm{Tg}-\mathrm{AD}$ mice, indicating a promising therapeutic approach for AD and related tauopathies ${ }^{[155-157]}$. The tau immunotherapy mechanisms remain unclear and this knowledge would promote the faster development of clinical trials and increase the probability to deliver the most successful immunotherapy for $\mathrm{AD}$ patients.

\section{CONCLUSIONS AND PERSPECTIVES}

Tau is a central molecule in the AD pathogenesis. Tau hyperphosphorylation, truncation, aggregation, and prion-like propagation provide novel paradigms for our present understanding of the AD pathogenesis. Recent studies have shown that tau oligomers, instead of fibrillar aggregates, are cytotoxic through disrupting synaptic function, causing neuronal death and the tau pathology spread in preclinical models of taumediated neurodegeneration in vitro and in vivo ${ }^{[158-160]}$. However, to properly understand $\mathrm{AD}$ and to create and improve novel disease-modifying treatments and diagnostic tools, knowledge of the detailed underlying mechanisms and the relevance of these alterations to clinical AD cases will be needed. Thus, the detection and elimination of toxic tau oligomers or seed-competent monomers, prior to the NTF and PHF formation in the $\mathrm{AD}$ early stages, can be crucial in the prevention of tau pathologies. Essays to improve tau immunotherapies are of similar relevance. Anti-tau vaccines and other passive/active immunotherapies presently submitted to clinical tests have great potential for future therapeutic applications.

\section{Open Access}

This article is licensed under a Creative Commons Attribution 4.0 International License https://creativecommons.org/licenses/by/4.0/), which permits use, sharing, adaptation, distribution and reproduction in any medium or format, as long as you give appropriate credit to the original author(s) and the source, provide a link to the Creative Commons licence, and indicate if changes were made. The images or other third party material in this article are included in the article's Creative Commons licence, unless indicated otherwise in a credit line to the material. If material is not included in the article's Creative Commons licence and your intended use is not permitted by statutory regulation or exceeds the permitted use, you will need to obtain permission directly from the copyright holder. To view a copy of this licence, visit http://creativecommons. org/licenses/by/4.0/.

\section{Conflict of Interest Statement}

The author declares there is no conflict of interest. 


\section{REFERENCES}

1 Grundke-Iqbal I, Iqbal K, Quinlan M, et al. Microtubuleassociated protein tau. A component of Alzheimer paired helical filaments. J Biol Chem, 1986,261(13):60846089

2 Arriagada PV, Growdon JH, Hedley-Whyte ET, et al. Neurofibrillary tangles but not senile plaques parallel duration and severity of Alzheimer's disease. Neurology, 1992,42(3 Pt 1):631-639

3 Riley KP, Snowdon DA, Markesbery WR. Alzheimer's neurofibrillary pathology and the spectrum of cognitive function: findings from the Nun Study. Ann Neurol, 2002,51(5):567-577

4 Kopke E, Tung YC, Shaikh S, et al. Microtubuleassociated protein tau. Abnormal phosphorylation of a non-paired helical filament pool in Alzheimer disease. J Biol Chem, 1993,268(32):24 374-24 384

5 Grundke-Iqbal I, Iqbal K, Tung YC, et al. Abnormal phosphorylation of the microtubule-associated protein tau (tau) in Alzheimer cytoskeletal pathology. Proc Natl Acad Sci USA, 1986,83(13):4913-4917

6 Alonso AC, Zaidi T, Grundke-Iqbal I, et al. Role of abnormally phosphorylated tau in the breakdown of microtubules in Alzheimer disease. Proc Natl Acad Sci USA, 1994,91(12):5562-5566

7 Alonso A, Zaidi T, Novak M, et al. Hyperphosphorylation induces self-assembly of tau into tangles of paired helical filaments/straight filaments. Proc Natl Acad Sci USA, 2001,98(12):6923-6928

8 Braak H, Del Tredici K. The pathological process underlying Alzheimer's disease in individuals under thirty. Acta Neuropathol, 2011,121(2):171-181

9 Braak H, Braak E. Neuropathological stageing of Alzheimer-related changes. Acta Neuropathol, 1991, 82(4):239-259

10 Braak H, Braak E. Staging of Alzheimer's diseaserelated neurofibrillary changes. Neurobiol Aging, 1995, 16(3):271-278

11 Grober E, Dickson D, Sliwinski MJ, et al. Memory and mental status correlates of modified Braak staging. Neurobiol Aging, 1999,20(6):573-579

12 Ahmed Z, Cooper J, Murray TK, et al. A novel in vivo model of tau propagation with rapid and progressive neurofibrillary tangle pathology: the pattern of spread is determined by connectivity, not proximity. Acta Neuropathol, 2014,127(5):667-683

13 Kumar H, Udgaonkar JB. Mechanistic approaches to understand the prion-like propagation of aggregates of the human tau protein. Biochim Biophys Acta Proteins Proteom, 2019,1867(10):922-932

14 Colin M, Dujardin S, Schraen-Maschke S, et al. From the prion-like propagation hypothesis to therapeutic strategies of anti-tau immunotherapy. Acta Neuropathol, 2020,139(1):3-25

15 Goedert M, Eisenberg DS, Crowther RA. Propagation of Tau Aggregates and Neurodegeneration. Annu Rev Neurosci, 2017,40:189-210

16 Goedert M, Spillantini MG, Jakes R, et al. Multiple isoforms of human microtubule-associated protein tau: sequences and localization in neurofibrillary tangles of Alzheimer's disease. Neuron, 1989,3(4):519-526

17 Iqbal K, Alonso Adel C, Chen S, et al. Tau pathology in Alzheimer disease and other tauopathies. Biochim Biophys Acta, 2005,1739(2-3):198-210

18 Kosik KS, Orecchio LD, Bakalis S, et al. Developmentally regulated expression of specific tau sequences. Neuron, 1989,2(4):1389-1397

19 Takuma H, Arawaka S, Mori H. Isoforms changes of tau protein during development in various species. Brain Res Dev Brain Res, 2003,142(2):121-127

20 Gendron TF, Petrucelli L. The role of tau in neurodegeneration. Mol Neurodegener, 2009,4:13

21 Mukrasch MD, Bibow S, Korukottu J, et al. Structural polymorphism of 441-residue tau at single residue resolution. PLoS Biol, 2009,7(2):e34

22 Papasozomenos SC, Binder LI. Phosphorylation determines two distinct species of Tau in the central nervous system. Cell Motil Cytoskeleton, 1987,8(3):210226

23 Trojanowski JQ, Schuck T, Schmidt ML, et al. Distribution of tau proteins in the normal human central and peripheral nervous system. J Histochem Cytochem, 1989,37(2):209-215

24 Iqbal K, Liu F, Gong CX. Recent developments with tau-based drug discovery. Expert Opin Drug Discov, 2018,13(5):399-410

25 Chu D, Liu F. Pathological Changes of Tau Related to Alzheimer's Disease. ACS Chem Neurosci, 2019,10(2): 931-944

26 Chidambaram H, Chinnathambi S. G-Protein Coupled Receptors and Tau-different Roles in Alzheimer's Disease. Neuroscience, 2020,438:198-214

27 Neddens J, Temmel M, Flunkert S, et al. Phosphorylation of different tau sites during progression of Alzheimer's disease. Acta Neuropathol Commun, 2018,6(1):52

28 Avila J, Lucas JJ, Perez M, et al. Role of tau protein in both physiological and pathological conditions. Physiol Rev, 2004,84(2):361-384

29 LaPointe NE, Morfini G, Pigino G, et al. The amino terminus of tau inhibits kinesin-dependent axonal transport: implications for filament toxicity. J Neurosci Res, 2009,87(2):440-451

30 Xia D, Li C, Gotz J. Pseudophosphorylation of Tau at distinct epitopes or the presence of the P301L mutation targets the microtubule-associated protein Tau to dendritic spines. Biochim Biophys Acta, 2015,1852(5): 913-924

31 Alonso AC, Grundke-Iqbal I, Iqbal K. Alzheimer's disease hyperphosphorylated tau sequesters normal tau into tangles of filaments and disassembles microtubules. Nat Med, 1996,2(7):783-787

32 Wang JZ, Grundke-Iqbal I, Iqbal K. Kinases and phosphatases and tau sites involved in Alzheimer neurofibrillary degeneration. Eur J Neurosci, 2007, 25(1):59-68

33 Pei JJ, Grundke-Iqbal I, Iqbal K, et al. Accumulation of cyclin-dependent kinase 5 (cdk5) in neurons with early stages of Alzheimer's disease neurofibrillary degeneration. Brain Res, 1998,797(2):267-277

34 Jin N, Yin X, Yu D, et al. Truncation and activation of GSK-3beta by calpain I: a molecular mechanism links to tau hyperphosphorylation in Alzheimer's disease. Sci Rep, 2015,5:8187

35 Jin N, Yin X, Gu J, et al. Truncation and Activation of Dual 
Specificity Tyrosine Phosphorylation-regulated Kinase 1A by Calpain I: A MOLECULAR MECHANISM LINKED TO TAU PATHOLOGY IN ALZHEIMER DISEASE. J Biol Chem, 2015,290(24):15 219-15 237

36 Llorach-Pares L, Nonell-Canals A, Avila C, et al. Kororamides, Convolutamines, and Indole Derivatives as Possible Tau and Dual-Specificity Kinase Inhibitors for Alzheimer's Disease: A Computational Study. Mar Drugs, 2018,16(10):386

37 Hanger DP, Anderton BH, Noble W. Tau phosphorylation: the therapeutic challenge for neurodegenerative disease. Trends Mol Med, 2009,15(3):112-119

$38 \mathrm{Wu}$ XL, Pina-Crespo J, Zhang YW, et al. Tau-mediated Neurodegeneration and Potential Implications in Diagnosis and Treatment of Alzheimer's Disease. Chin Med J (Engl), 2017,130(24):2978-2990

39 Reimer L, Betzer C, Kofoed RH, et al. PKR kinase directly regulates tau expression and Alzheimer's disease-related tau phosphorylation. Brain Pathol, 2020,27:1-17

40 Muralidar S, Ambi SV, Sekaran S, et al. Role of tau protein in Alzheimer's disease: The prime pathological player. Int J Biol Macromol, 2020,163:1599-1617

41 Liu F, Iqbal K, Grundke-Iqbal I, et al. Involvement of aberrant glycosylation in phosphorylation of tau by cdk5 and GSK-3beta. FEBS Lett, 2002,530(1-3): 209214

42 Woods YL, Cohen P, Becker W, et al. The kinase DYRK phosphorylates protein-synthesis initiation factor eIF2Bepsilon at Ser539 and the microtubule-associated protein tau at Thr212: potential role for DYRK as a glycogen synthase kinase 3-priming kinase. Biochem J, 2001,355(Pt 3):609-615

43 Liu F, Liang Z, Wegiel J, et al. Overexpression of Dyrk1A contributes to neurofibrillary degeneration in Down syndrome. FASEB J, 2008,22(9):3224-3233

44 Singh TJ, Zaidi T, Grundke-Iqbal I, et al. Modulation of GSK-3-catalyzed phosphorylation of microtubuleassociated protein tau by non-proline-dependent protein kinases. FEBS Lett, 1995,358(1):4-8

45 Sengupta A, Wu Q, Grundke-Iqbal I, et al. Potentiation of GSK-3-catalyzed Alzheimer-like phosphorylation of human tau by cdk5. Mol Cell Biochem, 1997,167(12):99-105

46 Gong CX, Liu F, Wu G, et al. Dephosphorylation of microtubule-associated protein tau by protein phosphatase 5. J Neurochem, 2004,88(2):298-310

47 Liu F, Grundke-Iqbal I, Iqbal K, et al. Contributions of protein phosphatases PP1, PP2A, PP2B and PP5 to the regulation of tau phosphorylation. Eur J Neurosci, 2005,22(8):1942-1950

48 Wasik U, Schneider G, Mietelska-Porowska A, et al. Calcyclin binding protein and Siah-1 interacting protein in Alzheimer's disease pathology: neuronal localization and possible function. Neurobiol Aging, 2013,34(5):1380-1388

49 Diaz-Hernandez M, Gomez-Ramos A, Rubio A, et al. Tissue-nonspecific alkaline phosphatase promotes the neurotoxicity effect of extracellular tau. J Biol Chem, 2010,285(42):32 539-32 548

50 Liu F, Iqbal K, Grundke-Iqbal I, et al. Dephosphorylation of tau by protein phosphatase 5: impairment in
Alzheimer's disease. J Biol Chem, 2005,280(3):17901796

51 Liang Z, Liu F, Iqbal K, et al. Decrease of protein phosphatase $2 \mathrm{~A}$ and its association with accumulation and hyperphosphorylation of tau in Down syndrome. J Alzheimers Dis, 2008,13(3):295-302

52 Qian W, Yin X, Hu W, et al. Activation of protein phosphatase $2 \mathrm{~B}$ and hyperphosphorylation of Tau in Alzheimer's disease. J Alzheimers Dis, 2011, 23(4):617627

53 Gong CX, Shaikh S, Wang JZ, et al. Phosphatase activity toward abnormally phosphorylated tau: decrease in Alzheimer disease brain. J Neurochem, 1995, 65(2):732-738

54 Gong CX, Singh TJ, Grundke-Iqbal I, et al. Phosphoprotein phosphatase activities in Alzheimer disease brain. J Neurochem, 1993,61(3):921-927

55 Wang Y, Yang R, Gu J, et al. Cross talk between PI3KAKT-GSK-3beta and PP2A pathways determines tau hyperphosphorylation. Neurobiol Aging, 2015,36(1): 188-200

56 Qian W, Shi J, Yin X, et al. PP2A regulates tau phosphorylation directly and also indirectly via activating GSK-3beta. J Alzheimers Dis, 2010,19(4):1221-1229

57 Chu D, Tan J, Xie S, et al. GSK-3beta is Dephosphorylated by PP2A in a Leu309 Methylation-Independent Manner. J Alzheimers Dis, 2016,49(2):365-375

58 Zilka N, Filipcik P, Koson P, et al. Truncated tau from sporadic Alzheimer's disease suffices to drive neurofibrillary degeneration in vivo. FEBS Lett, 2006, 580(15):3582-3588

59 Hasegawa M, Morishima-Kawashima M, Takio K, et al. Protein sequence and mass spectrometric analyses of tau in the Alzheimer's disease brain. J Biol Chem, 1992,267(24):17 047-17 054

60 Yang LS, Ksiezak-Reding H. Calpain-induced proteolysis of normal human tau and tau associated with paired helical filaments. Eur J Biochem, 1995,233(1):9-17

61 Basurto-Islas G, Gu JH, Tung YC, et al. Mechanism of Tau Hyperphosphorylation Involving Lysosomal Enzyme Asparagine Endopeptidase in a Mouse Model of Brain Ischemia. J Alzheimer Dis, 2018,63(2):821833

62 Gamblin TC, Chen F, Zambrano A, et al. Caspase cleavage of tau: linking amyloid and neurofibrillary tangles in Alzheimer's disease. Proc Natl Acad Sci USA, 2003,100(17):10 032-10 037

63 Zhang Z, Song M, Liu X, et al. Cleavage of tau by asparagine endopeptidase mediates the neurofibrillary pathology in Alzheimer's disease. Nat Med, 2014, 20(11):1254-1262

64 Wischik CM, Novak M, Thogersen HC, et al. Isolation of a fragment of tau derived from the core of the paired helical filament of Alzheimer disease. Proc Natl Acad Sci USA, 1988,85(12):4506-4510

65 de Calignon A, Fox LM, Pitstick R, et al. Caspase activation precedes and leads to tangles. Nature, 2010, 464(7292):1201-1204

66 Zhou Y, Shi J, Chu D, et al. Relevance of Phosphorylation and Truncation of Tau to the Etiopathogenesis of Alzheimer's Disease. Front Aging Neurosci, 2018,10:27

67 Li L, Jiang Y, Hu W, et al. Pathological Alterations 
of Tau in Alzheimer's Disease and 3xTg-AD Mouse Brains. Mol Neurobiol, 2019,56(9):6168-6183

68 Yin H, Kuret J. C-terminal truncation modulates both nucleation and extension phases of tau fibrillization. FEBS Lett, 2006,580(1):211-215

69 Berry RW, Abraha A, Lagalwar S, et al. Inhibition of tau polymerization by its carboxy-terminal caspase cleavage fragment. Biochemistry, 2003,42(27):83258331

$70 \mathrm{Gu} \mathrm{J}, \mathrm{Xu} \mathrm{W}$, Jin N, et al. Truncation of Tau selectively facilitates its pathological activities. J Biol Chem, 2020,295(40):13 812-13 828

71 Guo T, Noble W, Hanger DP. Roles of tau protein in health and disease. Acta Neuropathol, 2017,133(5):665704

72 Jadhav S, Katina S, Kovac A, et al. Truncated tau deregulates synaptic markers in rat model for human tauopathy. Front Cell Neurosci, 2015,9:24

73 Min SW, Cho SH, Zhou Y, et al. Acetylation of tau inhibits its degradation and contributes to tauopathy. Neuron, 2010,67(6):953-966

74 Cohen TJ, Guo JL, Hurtado DE, et al. The acetylation of tau inhibits its function and promotes pathological tau aggregation. Nat Commun, 2011,2:252

75 Cook C, Stankowski JN, Carlomagno Y, et al. Acetylation: a new key to unlock tau's role in neurodegeneration. Alzheimers Res Ther, 2014,6(3):29

76 Tracy T, Claiborn KC, Gan L. Regulation of Tau Homeostasis and Toxicity by Acetylation. Adv Exp Med Biol, 2019,1184:47-55

77 Cohen TJ, Constance BH, Hwang AW, et al. Intrinsic Tau Acetylation Is Coupled to Auto-Proteolytic Tau Fragmentation. PLoS One, 2016,11(7):e0158470

78 Julien C, Tremblay C, Emond V, et al. Sirtuin 1 reduction parallels the accumulation of tau in Alzheimer disease. $\mathrm{J}$ Neuropathol Exp Neurol, 2009,68(1):48-58

79 Lattanzio F, Carboni L, Carretta D, et al. Treatment with the neurotoxic Abeta (25-35) peptide modulates the expression of neuroprotective factors Pin1, Sirtuin 1 , and brain-derived neurotrophic factor in SH-SY5Y human neuroblastoma cells. Exp Toxicol Pathol, 2016, 68(5):271-276

80 Kreppel LK, Blomberg MA, Hart GW. Dynamic glycosylation of nuclear and cytosolic proteins. Cloning and characterization of a unique O-GlcNAc transferase with multiple tetratricopeptide repeats. J Biol Chem, 1997,272(14): 9308-9315

81 Gao Y, Wells L, Comer FI, et al. Dynamic O-glycosylation of nuclear and cytosolic proteins: cloning and characterization of a neutral, cytosolic beta-N-acetylglucosaminidase from human brain. J Biol Chem, 2001,276(13):9838-9845

82 Hart GW, Kreppel LK, Comer FI, et al. O-GlcNAcylation of key nuclear and cytoskeletal proteins: reciprocity with O-phosphorylation and putative roles in protein multimerization. Glycobiology, 1996,6(7):711-716

83 Haltiwanger RS, Blomberg MA, Hart GW. Glycosylation of nuclear and cytoplasmic proteins. Purification and characterization of a uridine diphospho-N-acetylglucosamine: polypeptide betaN-acetylglucosaminyltransferase. J Biol Chem, 1992, 267(13):9005-9013
84 Liu F, Iqbal K, Grundke-Iqbal I, et al. O-GlcNAcylation regulates phosphorylation of tau: a mechanism involved in Alzheimer's disease. Proc Natl Acad Sci USA, 2004,101(29):10 804-10 809

85 Arnold CS, Johnson GV, Cole RN, et al. The microtubule-associated protein tau is extensively modified with O-linked N-acetylglucosamine. J Biol Chem, 1996, 271(46):28741-28744

86 Liu F, Shi J, Tanimukai H, et al. Reduced O-GlcNAcylation links lower brain glucose metabolism and tau pathology in Alzheimer's disease. Brain, 2009,132(Pt 7):1820-1832

$87 \mathrm{Gu} \mathrm{J}$, Jin N, Ma D, et al. Calpain I Activation Causes GLUT3 Proteolysis and Downregulation of O-GlcNAcylation in Alzheimer's Disease Brain. J Alzheimers Dis, 2018,62(4):1737-1746

88 Hershko A, Ciechanover A. The ubiquitin system. Annu Rev Biochem, 1998,67: 425-479

89 Komander D. The emerging complexity of protein ubiquitination. Biochem Soc Trans, 2009,37(Pt 5):937953

90 Petrucelli L, Dickson D, Kehoe K, et al. CHIP and Hsp70 regulate tau ubiquitination, degradation and aggregation. Hum Mol Genet, 2004,13(7):703-714

91 Babu JR, Geetha T, Wooten MW. Sequestosome 1/ p62 shuttles polyubiquitinated tau for proteasomal degradation. J Neurochem, 2005,94(1):192-203

92 Mori H, Kondo J, Ihara Y. Ubiquitin is a component of paired helical filaments in Alzheimer's disease. Science, 1987,235(4796):1641-1644

93 Kuzuhara S, Mori H, Izumiyama N, et al. Lewy bodies are ubiquitinated. A light and electron microscopic immunocytochemical study. Acta Neuropathol, 1988, 75(4):345-353

94 Keller JN, Hanni KB, Markesbery WR. Impaired proteasome function in Alzheimer's disease. J Neurochem, 2000,75(1):436-439

95 Johnston JA, Ward CL, Kopito RR. Aggresomes: a cellular response to misfolded proteins. J Cell Biol, 1998,143(7):1883-1898

96 Cripps D, Thomas SN, Jeng Y, et al. Alzheimer diseasespecific conformation of hyperphosphorylated paired helical filament-Tau is polyubiquitinated through Lys48, Lys-11, and Lys-6 ubiquitin conjugation. J Biol Chem, 2006,281(16): 10 825-10 838

97 Kontaxi C, Piccardo P, Gill AC. Lysine-Directed Post-translational Modifications of Tau Protein in Alzheimer's Disease and Related Tauopathies. Front Mol Biosci, 2017,4:56

98 Chu TT, Gao N, Li QQ, et al. Specific Knockdown of Endogenous Tau Protein by Peptide-Directed UbiquitinProteasome Degradation. Cell Chem Biol, 2016, 23(4):453-461

99 Schweers O, Schonbrunn-Hanebeck E, Marx A, et al. Structural studies of tau protein and Alzheimer paired helical filaments show no evidence for beta-structure. J Biol Chem, 1994,269(39):24 290-24 297

100 von Bergen M, Friedhoff P, Biernat J, et al. Assembly of tau protein into Alzheimer paired helical filaments depends on a local sequence motif((306)VQIVYK(311)) forming beta structure. Proc Natl Acad Sci USA, 2000, 97(10):5129-5134 
101 Liu K, Liu Y, Li L, et al. Glycation alter the process of Tau phosphorylation to change Tau isoforms aggregation property. Biochim Biophys Acta, 2016,1862(2):192-201

102 Necula M, Kuret J. Pseudophosphorylation and glycation of tau protein enhance but do not trigger fibrillization in vitro. J Biol Chem, 2004,279(48):49 694-49 703

103 Quinn JP, Corbett NJ, Kellett KAB, et al. Tau Proteolysis in the Pathogenesis of Tauopathies: Neurotoxic Fragments and Novel Biomarkers. J Alzheimers Dis, 2018,63(1):1333

104 Jeganathan S, von Bergen M, Brutlach H, et al. Global hairpin folding of tau in solution. Biochemistry, 2006,45(7):2283-2293

105 Ferreon JC, Jain A, Choi KJ, et al. Acetylation Disfavors Tau Phase Separation. Int J Mol Sci, 2018,19(5):1360

106 Yuzwa SA, Cheung AH, Okon M, et al. O-GlcNAc modification of tau directly inhibits its aggregation without perturbing the conformational properties of tau monomers. J Mol Biol, 2014,426(8):1736-1752

107 Reynolds MR, Berry RW, Binder LI. Site-specific nitration differentially influences tau assembly in vitro. Biochemistry, 2005,44(42):13 997-14 009

108 Funk KE, Thomas SN, Schafer KN, et al. Lysine methylation is an endogenous post-translational modification of tau protein in human brain and a modulator of aggregation propensity. Biochem J, 2014, 462(1):77-88

109 Yoshitake J, Soeda Y, Ida T, et al. Modification of Tau by 8 -Nitroguanosine 3',5'-Cyclic Monophosphate (8-Nitro-cGMP): EFFECTS OF NITRIC OXIDELINKED CHEMICAL MODIFICATION ON TAU AGGREGATION. J Biol Chem, 2016,291(43):22 71422720

110 Luo HB, Xia YY, Shu XJ, et al. SUMOylation at K340 inhibits tau degradation through deregulating its phosphorylation and ubiquitination. Proc Natl Acad Sci USA, 2014,111(46):16 586-16 591

111 Guru KrishnaKumar V, Baweja L, Ralhan $\mathrm{K}$, et al. Carbamylation promotes amyloidogenesis and induces structural changes in Tau-core hexapeptide fibrils. Biochim Biophys Acta Gen Subj, 2018,1862(12):25902604

112 Rizzu P, Van Swieten JC, Joosse M, et al. High prevalence of mutations in the microtubule-associated protein tau in a population study of frontotemporal dementia in the Netherlands. Am J Hum Genet, 1999,64(2):414-421

113 Alonso Adel C, Mederlyova A, Novak M, et al. Promotion of hyperphosphorylation by frontotemporal dementia tau mutations. J Biol Chem, 2004,279(33):34 873-34 881

114 Lu M, Kosik KS. Competition for microtubule-binding with dual expression of tau missense and splice isoforms. Mol Biol Cell, 2001,12(1):171-184

115 Adams SJ, DeTure MA, McBride M, et al. Three repeat isoforms of tau inhibit assembly of four repeat tau filaments. PLoS One, 2010,55(5):e10810

116 Mudher A, Colin M, Dujardin S, et al. What is the evidence that tau pathology spreads through prion-like propagation? Acta Neuropathol Commun, 2017,5(1):99

117 Wang Y, Mandelkow E. Tau in physiology and pathology. Nat Rev Neurosci, 2016,17(1):5-21

118 Giustiniani J, Guillemeau K, Dounane O, et al. The
FK506-binding protein FKBP52 in vitro induces aggregation of truncated Tau forms with prion-like behavior. FASEB J, 2015,29(8):3171-3181

119 Wischik CM, Schelter BO, Wischik DJ, et al. Modeling Prion-Like Processing of Tau Protein in Alzheimer's Disease for Pharmaceutical Development. J Alzheimers Dis, 2018,62(3):1287-1303

120 Lee VM, Goedert M, Trojanowski JQ. Neurodegenerative tauopathies. Annu Rev Neurosci, 2001,24:11211159

121 Mamun AA, Uddin MS, Mathew B, et al. Toxic tau: structural origins of tau aggregation in Alzheimer's disease. Neural Regen Res, 2020,15(8):1417-1420

122 Holmes BB, DeVos SL, Kfoury N, et al. Heparan sulfate proteoglycans mediate internalization and propagation of specific proteopathic seeds. Proc Natl Acad Sci USA, 2013,110(33):E3138-3147

123 Falcon B, Cavallini A, Angers R, et al. Conformation determines the seeding potencies of native and recombinant Tau aggregates. J Biol Chem, 2015,290(2): 1049-1065

124 Maiza A, Chantepie S, Vera C, et al. The role of heparan sulfates in protein aggregation and their potential impact on neurodegeneration. FEBS Lett, 2018,592(23):38063818

125 Frost B, Jacks RL, Diamond MI. Propagation of tau misfolding from the outside to the inside of a cell. J Biol Chem, 2009,284(19):12 845-12 852

126 Shafiei SS, Guerrero-Munoz MJ, Castillo-Carranza DL. Tau Oligomers: Cytotoxicity, Propagation, and Mitochondrial Damage. Front Aging Neurosci, 2017,9: 83

127 Telling GC, Parchi P, DeArmond SJ, et al. Evidence for the conformation of the pathologic isoform of the prion protein enciphering and propagating prion diversity. Science, 1996,274(5295):2079-2082

128 Dujardin S, Commins C, Lathuiliere A, et al. Tau molecular diversity contributes to clinical heterogeneity in Alzheimer's disease. Nat Med, 2020,26(8):12561263

$129 \mathrm{Hu}$ W, Zhang X, Tung YC, et al. Hyperphosphorylation determines both the spread and the morphology of tau pathology. Alzheimers Dement, 2016,12(10):10661077

130 Miao J, Shi R, Li L, et al. Pathological Tau from Alzheimer's Brain Induces Site-Specific Hyperphosphorylation and SDS- and Reducing AgentResistant Aggregation of Tau in vivo. Front Aging Neurosci, 2019,11:34

131 Demaegd K, Schymkowitz J, Rousseau F. Transcellular Spreading of Tau in Tauopathies. Chembiochem, 2018, 19(23):2424-2432

132 Brunello CA, Merezhko M, Uronen RL, et al. Mechanisms of secretion and spreading of pathological tau protein. Cell Mol Life Sci, 2020,77(9):1721-1744

133 Ittner LM, Gotz J. Amyloid-beta and tau--a toxic pas de deux in Alzheimer's disease. Nat Rev Neurosci, 2011,12(2):65-72

$134 \mathrm{Ke}$ YD, Suchowerska AK, van der Hoven J, et al. Lessons from tau-deficient mice. Int J Alzheimers Dis, 2012,2012:873 270

135 Congdon EE, Sigurdsson EM. Tau-targeting therapies 
for Alzheimer disease. Nat Rev Neurol, 2018,14(7):399415

136 Wittrup A, Lieberman J. Knocking down disease: a progress report on siRNA therapeutics. Nat Rev Genet, 2015,16(9):543-552

137 Zuckerman JE, Davis ME. Clinical experiences with systemically administered siRNA-based therapeutics in cancer. Nat Rev Drug Discov, 2015,14(12):843-856

138 Santa-Maria I, Alaniz ME, Renwick N, et al. Dysregulation of microRNA-219 promotes neurodegeneration through post-transcriptional regulation of tau. J Clin Invest, 2015,125(2):681-686

139 Banzhaf-Strathmann J, Benito E, May S, et al. MicroRNA-125b induces tau hyperphosphorylation and cognitive deficits in Alzheimer's disease. EMBO J, 2014,33(15):1667-1680

140 Smith PY, Hernandez-Rapp J, Jolivette F, et al. miR$132 / 212$ deficiency impairs tau metabolism and promotes pathological aggregation in vivo. Hum Mol Genet, 2015,24(23):6721-6735

141 Liu W, Zhao J, Lu G. miR-106b inhibits tau phosphorylation at Tyr 18 by targeting Fyn in a model of Alzheimer's disease. Biochem Biophys Res Commun, 2016,478(2):852-857

142 Corey DR. Nusinersen, an antisense oligonucleotide drug for spinal muscular atrophy. Nat Neurosci, 2017, 20(4):497-499

143 Finkel RS, Chiriboga CA, Vajsar J, et al. Treatment of infantile-onset spinal muscular atrophy with nusinersen: a phase 2, open-label, dose-escalation study. Lancet, 2016,388(10063):3017-3026

144 Jadhav S, Avila J, Scholl M, et al. A walk through tau therapeutic strategies. Acta Neuropathol Commun, 2019,7(1):22

145 Noble W, Jimenez-Sanchez M, Perez-Nievas BG, et al. Considerations for future tau-targeted therapeutics: can they deliver? Expert Opin Drug Discov, 2020, 15(3):265-267

146 Levenson JM, Schroeter S, Carroll JC, et al. NPT088 reduces both amyloid-beta and tau pathologies in transgenic mice. Alzheimers Dement (N Y), 2016,2(3): 141-155

147 Seidler PM, Boyer DR, Rodriguez JA, et al. Structurebased inhibitors of tau aggregation. Nat Chem, 2018, 10(2):170-176

148 Jucker M, Walker LC. Self-propagation of pathogenic protein aggregates in neurodegenerative diseases. Nature, 2013,501(7465):45-51
149 Pooler AM, Polydoro M, Wegmann S, et al. Propagation of tau pathology in Alzheimer's disease: identification of novel therapeutic targets. Alzheimers Res Ther, 2013,5(5):49

150 Bakota L, Brandt R. Tau Biology and Tau-Directed Therapies for Alzheimer's Disease. Drugs, 2016,76(3): 301-313

151 Medina M. An Overview on the Clinical Development of Tau-Based Therapeutics. Int J Mol Sci, 2018,19(4):1160

152 Brunden KR, Zhang B, Carroll J, et al. Epothilone D improves microtubule density, axonal integrity, and cognition in a transgenic mouse model of tauopathy. $\mathrm{J}$ Neurosci, 2010,30(41):13 861-13 866

153 Zhang B, Carroll J, Trojanowski JQ, et al. The microtubule-stabilizing agent, epothilone $\mathrm{D}$, reduces axonal dysfunction, neurotoxicity, cognitive deficits, and Alzheimer-like pathology in an interventional study with aged tau transgenic mice. J Neurosci, 2012,32(11): 3601-3611

154 Boxer AL, Qureshi I, Ahlijanian M, et al. Safety of the tau-directed monoclonal antibody BIIB092 in progressive supranuclear palsy: a randomised, placebocontrolled, multiple ascending dose phase $1 \mathrm{~b}$ trial. Lancet Neurol, 2019,18(6): 549-558

155 Dai CL, Chen X, Kazim SF, et al. Passive immunization targeting the $\mathrm{N}$-terminal projection domain of tau decreases tau pathology and improves cognition in a transgenic mouse model of Alzheimer disease and tauopathies. J Neural Transm(Vienna), 2015,122(4):607617

156 Dai CL, Tung YC, Liu F, et al. Tau passive immunization inhibits not only tau but also Abeta pathology. Alzheimers Res Ther, 2017,9(1):1

157 Dai CL, Hu W, Tung YC, et al. Tau passive immunization blocks seeding and spread of Alzheimer hyperphosphorylated Tau-induced pathology in $3 \mathrm{x}$ TgAD mice. Alzheimers Res Ther, 2018,10(1):13

158 Flach K, Hilbrich I, Schiffmann A, et al. Tau oligomers impair artificial membrane integrity and cellular viability. J Biol Chem, 2012,287(52):43 223-43 233

159 Guerrero-Munoz MJ, Gerson J, Castillo-Carranza DL. Tau Oligomers: The Toxic Player at Synapses in Alzheimer's Disease. Front Cell Neurosci, 2015,9:464

160 Gerson JE, Sengupta U, Kayed R. Tau Oligomers as Pathogenic Seeds: Preparation and Propagation In Vitro and In Vivo. Methods Mol Biol, 2017,1523:141-157

(Received Nov. 3, 2020; accepted Dec. 3, 2020) 